\title{
FERRAMENTAS BIM COMO APOIO AO EaD EM ARQUITETURA
}

Modalidade: Planejamento de inserção de BIM na educação

\section{PROCESSO}

0 antes: Sugere-se que seja feito um levantamento junto ao colegiado do curso sobre ferramentas BIM que podem ser adaptadas do mercado de trabalho para 0 ensino de projeto de Arquitetura.

0 durante: Escolhida a ferramenta, seguem-se os 5 passos apresentados ao lado. Aconselha-se que se aplique em turmas a partir da metade do curso.

0 depois: É primordial que seja descrita a experiência por meio de artigos científicos, reportagens, vídeos e outras mídias e que um novo ciclo seja retroalimentado pelas conclusões.

Figura 1: Interface da ferramenta identificada na Empresa A como potencial para estudo de caso.
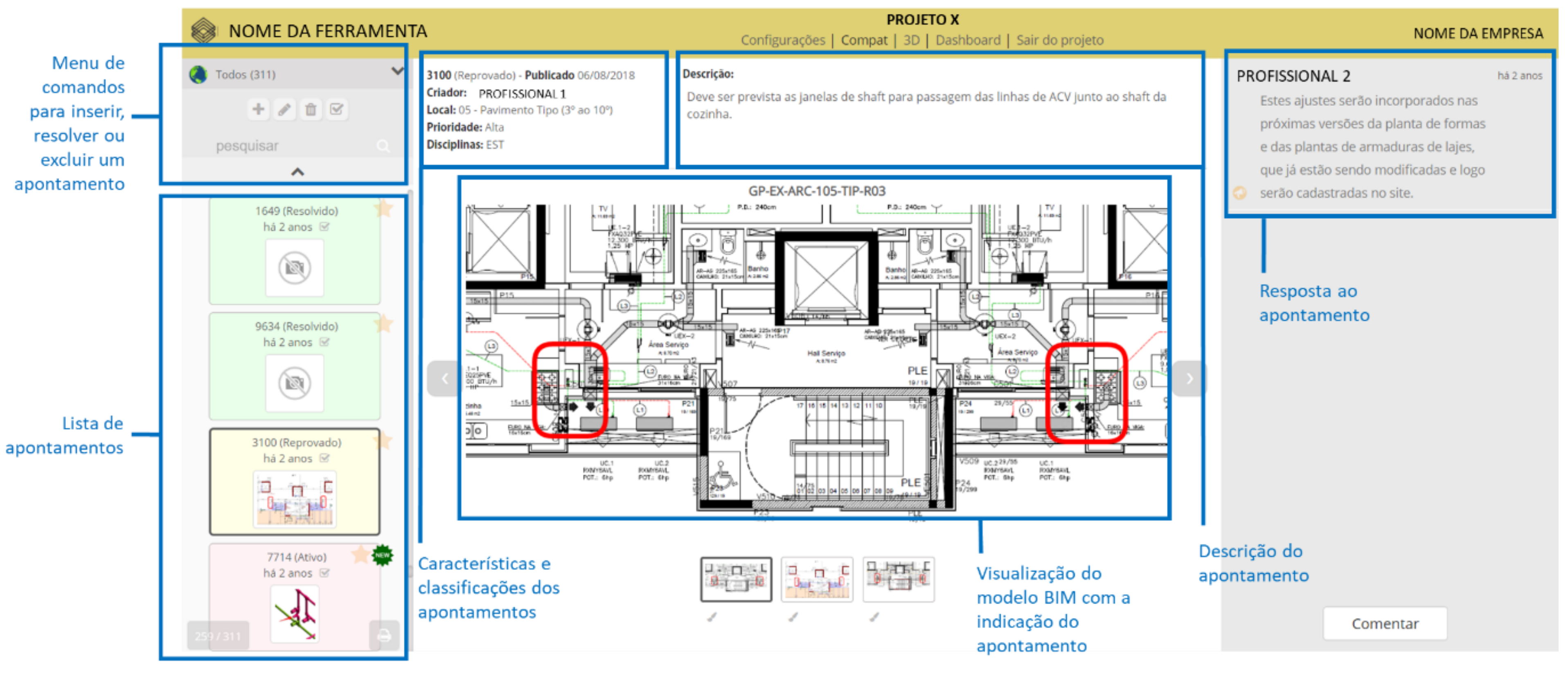

\section{TECNOLOGIAS}

A ferramenta identificada como potencial para um primeiro estudo de caso (ainda não conduzido) consiste em um portal online desenvolvido pela Empresa A para a visualização dos seus relatórios de compatibilização de projetos com base no modelo BIM. Seu objetivo é concentrar as informações, facilitar a comunicação e documentar as tomadas de decisão referentes ao projeto. A plataforma contém visualizador e espaço para interação mediante comentários. 0 acesso é via navegadores de internet, portanto não é necessário instalar qualquer software específico.
Passo 1: Formalização de convênio da instituição de ensino com a empresa.

Passo 2: Empresa apresenta a ferramenta para os alunos e demonstra como ela é utilizada no processo de projeto real.

Passo 3: Demonstração do professor sobre como a ferramenta será utilizada no exercício de projeto acadêmico.

Passo 4: Projeto é desenvolvido ao longo do período mediado pelo professor através da ferramenta.

Passo 5: Apresentação da Universidade para a Empresa com feedback sobre a ferramenta. EaD em Arquitetura com base em BIM.
Caroline Kehl 1

1- ULBRA, keh..caroline@gmail.com

\section{INTRODUÇÃO}

Esta pesquisa é fruto do TCC escrito em função de curso de pós-graduação em Educação (KEHL, 2020). 0 escopo do trabalho encontra-se no ensino superior de graduação em Arquitetura. Mais precisamente, discute a tendência de colaboração entre o mercado da Indústria da Construção Civil e a academia no intuito de explorar 0 uso de ferramentas de comunicação específicas para 0 desenvolvimento de projetos desenvolvidas no mercado a serem transpostas para 0 ensino.

\section{Atualmente, vivenciam-se} importantes marcos históricos dentro dos setores. Ao longo da última década, a indústria da construção vem vivendo uma transformação tecnológica sem precedentes em relação à substituição da plataforma CAD (Computer Aided Design) para a BIM (Building Information Modeling). Paralelamente, na educação vem ocorrendo a transição do ensino presencial para 0 ensino a distância. A percepção de que há uma conveniente intersecção nos conjuntos de saberes destes dois campos provocou o desejo de aproximá-los.

KEHL, C. Ferramentas BIM como apoio ao EaD em Arquitetura. Trabalho de Conclusão de Curso (Especialização A Moderna Educação: Metodologias Tendências e Foco no Aluno). Pontifícia Universidade Católica do Rio Grande do Sul. Porto Alegre, 2020. 